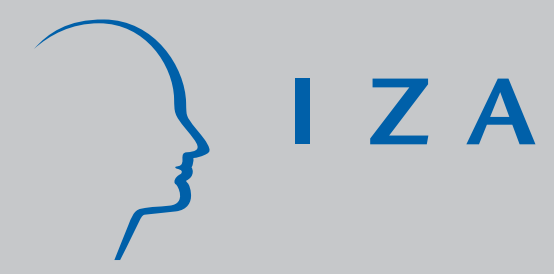

IZA DP No. 4134

Assessing the Impact of a Wage Subsidy for Single Parents on Social Assistance in Canada

Guy Lacroix

April 2009 


\title{
Assessing the Impact of a Wage Subsidy for Single Parents on Social Assistance in Canada
}

\author{
Guy Lacroix \\ Université Laval, \\ CIRPÉE and IZA \\ Discussion Paper No. 4134 \\ April 2009 \\ IZA \\ P.O. Box 7240 \\ 53072 Bonn \\ Germany \\ Phone: +49-228-3894-0 \\ Fax: +49-228-3894-180 \\ E-mail: iza@iza.org
}

Any opinions expressed here are those of the author(s) and not those of IZA. Research published in this series may include views on policy, but the institute itself takes no institutional policy positions.

The Institute for the Study of Labor (IZA) in Bonn is a local and virtual international research center and a place of communication between science, politics and business. IZA is an independent nonprofit organization supported by Deutsche Post Foundation. The center is associated with the University of Bonn and offers a stimulating research environment through its international network, workshops and conferences, data service, project support, research visits and doctoral program. IZA engages in (i) original and internationally competitive research in all fields of labor economics, (ii) development of policy concepts, and (iii) dissemination of research results and concepts to the interested public.

IZA Discussion Papers often represent preliminary work and are circulated to encourage discussion. Citation of such a paper should account for its provisional character. A revised version may be available directly from the author. 


\section{ABSTRACT}

\section{Assessing the Impact of a Wage Subsidy for Single Parents on Social Assistance in Canada ${ }^{*}$}

In 2002 the Quebec government implemented the "Action Emploi" (AE) program aimed at making work pay for long-term social assistance recipients (SA). AE offered a generous wage subsidy that could last up to three years to recipients who found a full-time job within twelve months. The program was implemented on an experimental basis for a single year. Based on little empirical evidence, a slightly modified version of the program was implemented on permanent basis in May 2008. The paper investigates the impact of the temporary program by focusing on the labour market transitions of the targeted population starting one year before the implementation of the program and up until the end of 2005. We use a multi-state multi-episode model. The endogeneity of the participation status is accounted for by treating $A E$ as a distinct state and by allowing correlated unobserved factors to affect the transitions. The model is estimated by the method of simulated moments. Our results show that $A E$ has indeed increased the duration of Off-SA spells and decreased the duration of SA spells slightly. There is also some evidence that the response to the program varies considerably with unobserved individual characteristics.

JEL Classification: $\quad$ I38, J31, J64

Keywords: $\quad$ wage subsidy, multi-state multi-episode transition model, social assistance

Corresponding author:

Guy Lacroix

Department of Economics

Pavillon de Sève

Université Laval

Québec

Canada G1K 7P4

E-mail: Guy.Lacroix@ecn.ulaval.ca

\footnotetext{
* The author is grateful to participants at the Canadian Labour Market and Skills Researcher Network workshop held in Toronto on November 18 and 192008 for useful comments, and in particular to Dwayne Benjamin and Benoît Delage.
} 


\section{Introduction}

In seeking to alleviate the problems that plague particularly disadvantaged groups when integrating the labour market, governments have traditionally turned to skill enhancing training programs. By enhancing skills, it was hoped that individuals would receive attractive job offers and thus reduce their reliance on transfer programs. Over the past twenty years, the evaluation literature has generally found training programs to have had limited success in achieving these goals [see Heckman, LaLonde and Smith (1999) for a recent and detailed survey and Gilbert, Kamionka and Lacroix (2001) for results pertaining to Canada]. Indeed, only very focused programs targeted at specific groups seem to have had any significant impact on reliance toward support programs. Yet, decrease in reliance has not generally translated into significant reductions in poverty rates.

Many governments have responded to such deceptive results by shying away from traditional training programs and by focusing instead on policies that directly address the relative (un)attractiveness of work. By directly subsidizing wage rates, it is believed many will be induced to accept job offers that would not normally be good alternatives to transfer programs such as social assistance (SA). Inducing individuals to work is motivated by two separate but complementary goals. First, by raising total income such policies may be more effective at addressing poverty than traditional programs. Second, holding a regular job may be conducive to the acquisition of skills and attitudes that are necessary for self-reliance.

Making work pay can be achieved in various ways. In the United States and in the United Kingdom, tax credits and other employment-conditional benefits designed to "make work pay" for low-income workers have been in place for a number of years. ${ }^{1}$ One of the objectives of earned income tax credits is to encourage SA recipients to engage in paid employment through the provision of an earned income supplement that offsets the loss of benefits and/or increased taxation and other costs associated with employment. In Canada, the Working Income Tax Benefit (WITB) was introduced in March 2007. The WITB aims at improving the incentives to work for low-income Canadians and to lower the so-called "welfare wall". The program is a refundable tax credit intended to provide tax relief for eligible working low income individuals and families who are already in the workforce and to encourage others to enter the workforce. The program thus shares many similarities with the EITC and the WFTC.

Prior to implementing the WITB, a policy aiming at helping single parents on social assistance become self-reliant was implemented on an experimental basis. The Self-Sufficiency Project (SSP) was a research and demonstration project that provided a generous, time-limited earnings supplement to SA recipients who found a full-time job and left the rolls. Most evaluations of the SSP have concluded that the program has had sizeable impacts on exits from SA [Michalopoulos, Card, Gennetian, Harknett and Robins (2000), Quets, Robins, Paan, Michalopoulos and Card (1999)]. Others have found the program beneficial to children [Morris

\footnotetext{
${ }^{1}$ The Earned Income Tax Credit (EITC) program in the US and the Working Families Tax Credit (WFTC) in the UK.
} 
and Michalopoulos (2000)] and to have had ambiguous results on marital behaviour [Harknett and Gennetian (2001)]. Yet, recent papers that use data for a longer period have found the program to have had at best a temporary effect on SA exits [Card and Hyslop (2005)] or to have had no impact at all once general equilibrium effects are accounted for [Lise, Seitz and Smith (2005)].

Early results from the SSP prompted the Quebec government to implement the "Action Emploi" (AE) program aimed at making work pay for long-term social assistance beneficiaries. Like SSP, AE offered a generous wage subsidy to those recipients who left SA within twelve months to take a full-time job. Like SSP, recipients were entitled to three years of benefits. But unlike SPP, the subsidy was not proportional to earned income. ${ }^{2}$ The AE program was implemented on an experimental basis for a single year. ${ }^{3}$ Very little research has looked into the impact of the program on the employment history of the targeted population. Yet, a modified version of the program was implemented on permanent basis in April 2008. The unique features of $\mathrm{AE}$ (universal accessibility, large-scale program, substantial financial incentives, etc.) offer a unique opportunity to document the impact of a SSP-like program on the response of long-term heterogeneous groups of SA recipients in a "real-world" setting. The purpose or this paper is to document the impact of a generous wage subsidy designed for long-term welfare recipients in the Canadian context. We do this by modelling the main features of the program. We focus on the transitions on the labour market starting one year before the implementation of the program and up until the end of 2005. We use a multi-state multi-episode model. The endogeneity of the participation status is accounted for by treating AE as a distinct state and by allowing correlated unobserved factors to affect the transitions between different states. Our results show that AE has indeed increased the duration of Off-SA spells and decreased the duration of SA spells slightly. There is also some evidence that the response to the program varies considerably with unobserved individual characteristics. Given that only $6 \%$ of the eligible population actually participated in the program, one can conjecture that a larger participation rate would have translated into larger program effects. This conjecture will eventually lend itself to investigation as the new permanent program gets more widely known and as more data become available.

\section{The Action Emploi Program}

The AE program was implemented on December $1^{\text {st }} 2001$. Income supplements were paid out as early as January $1^{\text {st }} 2002$. The program targeted long-term SA recipients with little work readiness and poor education. Thus to be eligible for $\mathrm{AE}, \mathrm{SA}$ recipients had to have claimed benefits for at least 36 months out of the last 45 prior to signing-up. Individuals could register at any time between December $1^{\text {st }} 2001$ and November $30^{\text {th }} 2002$ if they met that requirement

\footnotetext{
${ }^{2}$ It has been argued that linking the subsidy to earned income may result in self-selection into the program. See e.g. Brouillette and Lacroix (2008).

${ }^{3}$ Those who qualified within 12 months after the implementation of the program were entitled to three years of benefits, i.e. until December 2005 at the latest.
} 
in any given month during that period. The figure below shows the two main periods of the program. The first to register (early December 2001) could receive income supplements until the end of November 2004. Those who registered last (end of November 2002) could receive the supplement until the end of November 2005.

Figure 1: Action Emploi - Timeline

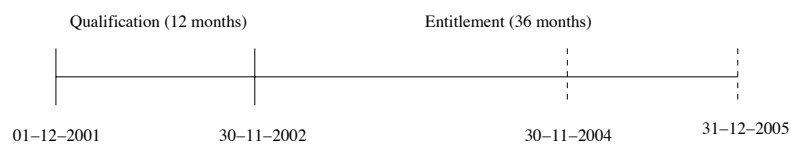

To qualify for the benefits, SA recipients had to find a full-time job (130 hours per month) and earn a gross wage that was at least equivalent to the minimum wage rate. The selfemployed were also eligible. To qualify, their net earnings had to be at least equivalent to a full-time minimum wage job. ${ }^{4}$

Receipt of the earnings supplement was conditional on working at least 130 hours per month. Those who did not meet the condition in any given month kept their entitlement during a grace period that lasted up to four months. They were automatically disqualified if they did not meet the requirement during the fourth month. Contrary to SSP, then benefits were not tied to monthly earnings. ${ }^{5}$ Instead they were set to $390 \$ /$ month during the first year of eligibility, and to $260 \$ /$ month and $130 \$ /$ month in the second and third year of eligibility, respectively. ${ }^{6}$

\subsection{Characteristics of the AE participants and Empirical Evidence}

In the months leading to the implementation of the program, SA recipients were sent a letter along with their benefits that detailed the main parameters of the program. They were

\footnotetext{
${ }^{4}$ The thresholds were changed twice due to changes in the provincial minimum wage rate:

- 910\$: December $1^{\text {st }} 2001$ - September $30^{\text {th }} 2002(130 \times 7.00 \$)$.

- 936\$: October $1^{\text {st }} 2002$ - January $31^{\text {st }} 2003(130 \times 7.20 \$)$.

- $949 \$$ : February $1^{\text {st }} 2003-(130 \times 7.30 \$)$.

${ }^{5}$ In the SSP, the benefits are roughly equivalent to: $B=0.50 \times(37,500 \$-w h)$, where $w$ is the hourly wage rate and $h$ is the annual hours of work. Consequently the benefits are a decreasing function of earnings. This may generate serious self-selection problems in the experiment. See Brouillette and Lacroix (2008) and Kamionka and Lacroix (2009).

${ }^{6}$ This is more or less equivalent to $43 \%, 28 \%$ and $14 \%$ of a full-time minimum wage job in each of the entitlement years. The program that was implemented in April 2008 is know as "Supplément à la prime au travail ". It provides a monthly supplement of $200 \$$ for a maximum of 12 months to SA recipients who work full-time and had a cumulative stay of 36 months over the last 42 prior to finding a job.
} 
also reminded about the program whenever they met with their caseload worker. According to government reports, 13,244 SA recipients signed-up for AE between December 2001 and November 2002. The table below shows the main characteristics of the participants. The majority are either singles or single parents. They are also relatively poorly educated. Over $75 \%$ of the participants have earned at most a high-school degree. The last panel of the table also indicates that the vast majority have very little attachment to the labour market. Indeed nearly $44 \%$ of the participants have had cumulative stays on SA of between 4 and 10 years prior to their participation, and over $48 \%$ of them have had cumulative stays of over 10 years.

Table 1: Characteristics of the AE participants

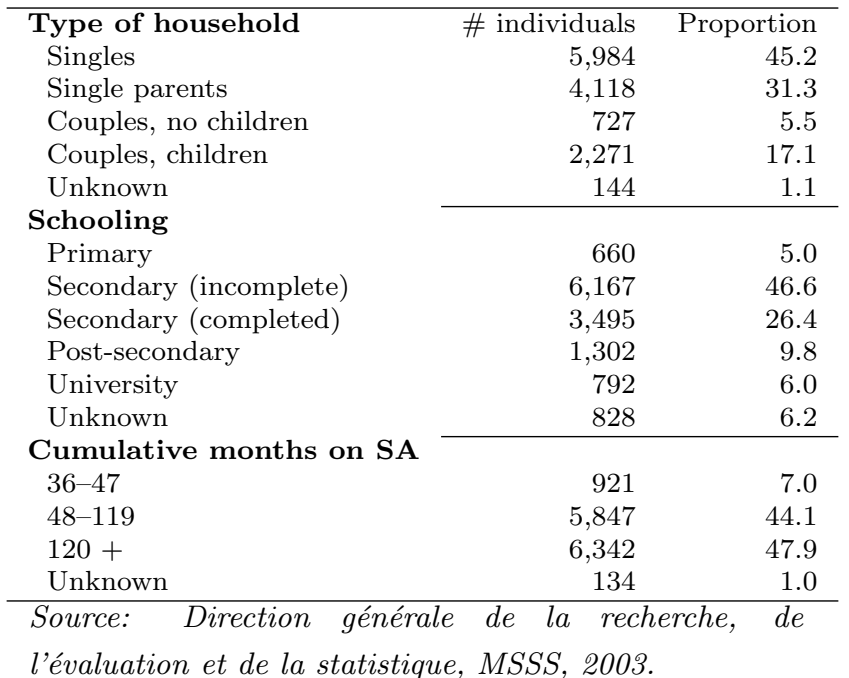

The empirical analysis is based on the administrative records of the Ministère de l'emploi et de la Solidarité sociale du Québec (MESS). The data span the period from January 2000 until December 2005. The files include detailed information on household type, number of children, region of residence, gender, schooling, birthplace, and monthly indicators on SA/AE participation.

We focus exclusively on single parents to allow a comparison with SSP. The files show that over 51,118 single parents satisfied the requirements for $\mathrm{AE}$ at the time of its implementation. In all, 3,807 individuals qualified for benefits. ${ }^{7}$ The main statistical features of our sample are reported in Table 2. Interestingly, there are very few noteworthy differences between participants and non-participants. Both groups are thus composed almost entirely of women born in Canada and who have approximately the same number of children. Participants are slightly younger and more educated. Likewise, the geographical distribution of the two

\footnotetext{
${ }^{7}$ The are 4,118 single parents in the administrative files. A total of 311 observations are omitted due to missing data.
} 
groups is very similar, albeit the fact that proportionally fewer participants live in the Greater Montreal area.

Table 2: Sample Characteristics

\begin{tabular}{|c|c|c|c|c|}
\hline \multirow[t]{3}{*}{ Variable } & \multicolumn{2}{|c|}{$\mathrm{AE}$} & \multicolumn{2}{|c|}{ Non-AE } \\
\hline & Mean & Std & Mean & Std \\
\hline & & Err & & Err \\
\hline Age & 33.712 & 7.772 & 35.107 & 9.647 \\
\hline Education & 11.054 & 2.236 & 10.374 & 2.590 \\
\hline Number of children & 1.586 & 0.870 & 1.520 & 0.871 \\
\hline Gender ( $1=$ Female $)$ & 0.879 & 0.326 & 0.870 & 0.337 \\
\hline Born in Canada & 0.816 & 0.387 & 0.816 & 0.387 \\
\hline \multicolumn{5}{|l|}{ Region of residence } \\
\hline Bas St-Laurent & 0.025 & & 0.019 & \\
\hline Saguenay - Lac St-Jean & 0.040 & & 0.039 & \\
\hline Capitale-Nationale & 0.093 & & 0.070 & \\
\hline Mauricie & 0.078 & & 0.067 & \\
\hline Estrie & 0.049 & & 0.033 & \\
\hline Montréal & 0.179 & & 0.255 & \\
\hline Outaouais & 0.038 & & 0.044 & \\
\hline Abitibi-Témiscamingue & 0.022 & & 0.022 & \\
\hline Côte-Nord & 0.018 & & 0.015 & \\
\hline Nord du Québec & 0.002 & & 0.003 & \\
\hline Gaspésie - Iles de la Madeleine & 0.029 & & 0.020 & \\
\hline Chaudière -Appalaches & 0.029 & & 0.027 & \\
\hline Laval & 0.024 & & 0.030 & \\
\hline Lanaudière & 0.062 & & 0.046 & \\
\hline Laurentides & 0.071 & & 0.052 & \\
\hline Montérégie & 0.150 & & 0.141 & \\
\hline Centre du Québec & 0.011 & & 0.007 & \\
\hline Montréal banlieue & 0.083 & & 0.109 & \\
\hline Number of observations & 3807 & & 47311 & \\
\hline
\end{tabular}

Despite the two groups being observationally very similar, the differences between the two groups are nevertheless statistically significant. Table 3 reports the results of fitting a simple probit regression of $\mathrm{AE}$ participation. It turns out most parameters are highly statistically significant and corroborate the findings of Table 2. In particular, participation increases with education and decreases with age. Likewise, participation rates are everywhere higher than in the metropolitan area of Montreal. These results suggest that participation in AE must be conditioned on observed characteristics.

\subsection{Transitions on the labour market}

Individual histories are derived from administrative records. Our analysis starts in January 2000 , one year prior to the implementation of AE. Four different states on the labour market can be determined from the data: (1) Off-SA; (2) SA; (3) AE; (4) AE-SA. Off-SA simply refers to not being on the rolls. Individuals in this situation may be employed, ineligible for SA benefits, or may be collecting employment insurance benefits. SA and AE are mutually exclusive states. Finally AE-SA refers to the grace period, i.e. to AE participants who are unemployed in a 
Table 3: Probit Regression: AE Participation

\begin{tabular}{|c|c|c|c|}
\hline Variable & $\begin{array}{c}\text { Marginal } \\
\text { Effect } \\
(\partial \Phi / \partial X)\end{array}$ & T-Stat & P-Value \\
\hline Age & -0.001 & -9.06 & 0.000 \\
\hline Education & 0.008 & 16.48 & 0.000 \\
\hline Number of Children & 0.007 & 5.69 & 0.000 \\
\hline Gender (1=Female) & 0.005 & 1.58 & 0.114 \\
\hline Born in Canada & -0.003 & -0.91 & 0.362 \\
\hline Region of residence (Montreal om & & & \\
\hline Bas St-Laurent & 0.060 & 6.00 & 0.000 \\
\hline Saguenay - Lac St-Jean & 0.032 & 4.53 & 0.000 \\
\hline Capitale-Nationale & 0.053 & 9.38 & 0.000 \\
\hline Mauricie & 0.042 & 7.40 & 0.000 \\
\hline Estrie & 0.063 & 8.24 & 0.000 \\
\hline Outaouais & 0.017 & 2.55 & 0.011 \\
\hline Abitibi-Témiscamingue & 0.029 & 3.19 & 0.001 \\
\hline Côte-Nord & 0.050 & 4.46 & 0.000 \\
\hline Nord du Québec & -0.000 & -0.01 & 0.995 \\
\hline Gaspésie - Iles de la Madeleine & 0.069 & 7.09 & 0.000 \\
\hline Chaudière -Appalaches & 0.036 & 4.34 & 0.000 \\
\hline Laval & 0.008 & 1.03 & 0.305 \\
\hline Lanaudière & 0.056 & 8.43 & 0.000 \\
\hline Laurentides & 0.056 & 8.84 & 0.000 \\
\hline Montérégie & 0.032 & 7.48 & 0.000 \\
\hline Centre du Québec & 0.060 & 3.96 & 0.000 \\
\hline Montréal banlieue & 0.004 & 0.88 & 0.379 \\
\hline Log likelihood & \multicolumn{3}{|c|}{$-13,230.965$} \\
\hline
\end{tabular}


given month but who are still eligible for benefits. Recall that the grace period may only last for a maximum of four months. From these four states, as many as twelve different transitions can potentially be observed. All spells are censored in December 2005. Tables 4 and 5 report the observed transitions for participants and non-participants separately. Non-participants can only be observed transiting between Off-SA and SA. The upper panel of Table 4 focuses on spells that were ongoing in January 2000. Over 6,176 individuals who were originally in the Off-SA state moved into SA within 12.9 months on average. On the other hand, over 22,359 individuals transited from SA into Off-SA within 39.6 months on average. Of greater concern is the fact that close to $46 \%(18,776 / 41,135)$ of those who were SA beneficiaries in January 2000 were still claiming benefits in December 2005. The lower panel of the table reports the frequency of subsequent transitions. Overall, the non-participants have experienced on average 1.62 transitions on the labour market.

Table 5 reports similar frequencies for participants over the same period. Of the 2,470 individuals on SA in January 2000, 967 moved directly into AE, while another 203 moved directly into AE-SA. ${ }^{8}$ The lower panel of the table shows a lot of movement between the different states. Participants have thus experienced 4.5 transitions on average over the period of analysis.

Table 4: Sample Transition Frequencies : Non-Participants

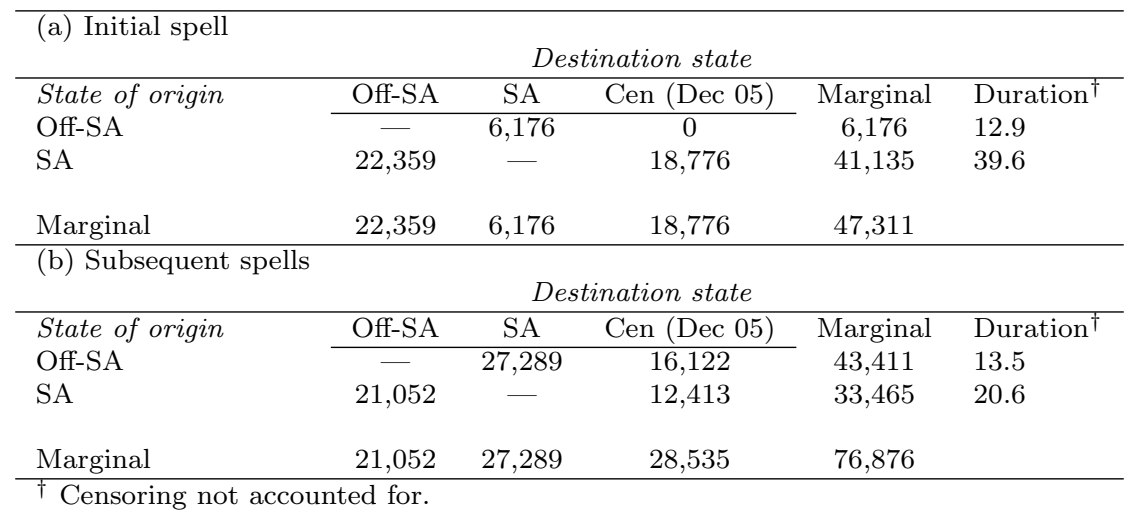

To help make sense of these tables, Figure 2 depicts the smoothed hazard rates of the transitions between SA and Off-SA for both participants and non-participants. No distinction is made between pre and post $\mathrm{AE}$ and the calculations are based on the second and subsequent spells only to avoid left-censored spells. According to the figure, participants have both lower transition rates between Off-SA and SA and higher transitions rates between SA and OffSA. ${ }^{9}$ It would thus be tempting to conclude that the program decreases the proportion of time spent on SA. Yet the hazard functions do not distinguish between pre and post $\mathrm{AE}$

\footnotetext{
${ }^{8}$ Those who moved into AE-SA were simultaneously receiving SA benefits and working too few hours to qualify for AE.

${ }^{9}$ The null assumption that the underlying survival functions are identical in both figures is strongly rejected.
} 
Table 5: Sample Transition Frequencies : Participants

\begin{tabular}{|c|c|c|c|c|c|c|c|}
\hline \multicolumn{8}{|c|}{ Destination state } \\
\hline State of origin & Off-SA & SA & $\mathrm{AE}$ & AE-SA & Cen (Dec 05) & Marginal & Duration $^{\dagger}$ \\
\hline Off-SA & - & 165 & 2 & 0 & 0 & 167 & 3.8 \\
\hline SA & 2,470 & - & 967 & 203 & 0 & 3,640 & 22.6 \\
\hline Marginal & 2,470 & 165 & 969 & 203 & 0 & 3,807 & \\
\hline \multicolumn{8}{|c|}{ Destination state } \\
\hline State of origin & Off-SA & $\mathrm{SA}$ & $\mathrm{AE}$ & AE-SA & Cen (Dec 05) & Marginal & Duration $^{\dagger}$ \\
\hline Off-SA & - & 3,214 & 2,080 & 30 & 2,776 & 8,100 & 8.9 \\
\hline SA & 2,567 & - & 435 & 90 & 830 & 3,922 & 9.7 \\
\hline $\mathrm{AE}$ & 2,989 & 71 & - & 807 & 197 & 4,064 & 18.4 \\
\hline AE-SA & 74 & 472 & 580 & - & 4 & 1,130 & 2.4 \\
\hline Marginal & 5,630 & 3,757 & 3,095 & 927 & 3807 & 17,216 & \\
\hline
\end{tabular}

${ }^{\dagger}$ Censoring not accounted for.

participation, nor do they account for potential selection into AE. Thus only an in-depth econometric analysis can measure precisely the contribution of the AE program on the relative attachment of participants to the labour market. In particular, a multi-state multi-episode model will allow us to determine the "steady-state" proportion of time spent on and off SA for participants and non-participants alike [see Eberwein, Ham and LaLonde (2002), Bonnal, Fougère and Sérandon (1997), and Gilbert et al. (2001)].

Figure 2: Smoothed empirical hazard rates
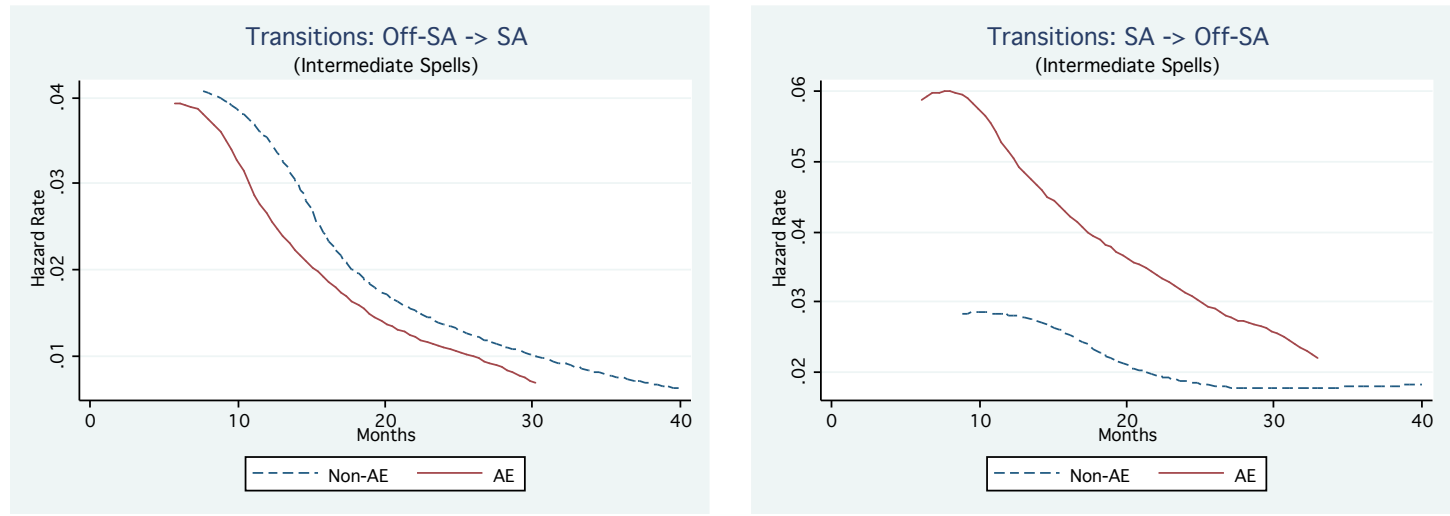


\section{The econometric model}

Multi-state multi-episode models are well suited to address the potential problem of endogenous participation in AE. ${ }^{10}$ Furthermore, once the entitlement phase ends, and given participation was properly modelled, the subsequent transitions can be conditioned on past participation. The model can thus determine the extent to which post-program durations on and off SA are affected by AE. The identification of the AE effect rests on the presence of a control group composed of those who did qualify but did not participate.

Each individual in our sample qualified for $\mathrm{AE}$ at the time of its implementation in December 2001. Figure 3 below depicts the work history of hypothetical non-participants and participants, respectively. The dashed vertical lines delimit the period of observation. The left hand-side figure shows that a typical non-participant will be observed in the SA state at the beginning of January 2000. The spell is left-censored as we only observe the residual duration that lasts up until June 2001, say. ${ }^{11}$ She then leaves SA for approximately 33 months, and then returns to SA until the end of December 2005. All spells are right censored in December 2005. The typical participant exhibits similar transitions. Upon leaving SA she enters AE for approximately 10 months. She loses her job and transits into the SA-AE state for 3 months. Upon finding a new job, she returns to AE for a spell of about 2 years. She next returns to SA for a short period and moves into Off-SA until the end of the period of observation.

Figure 3: Employment history of hypothetical non-participants and participants
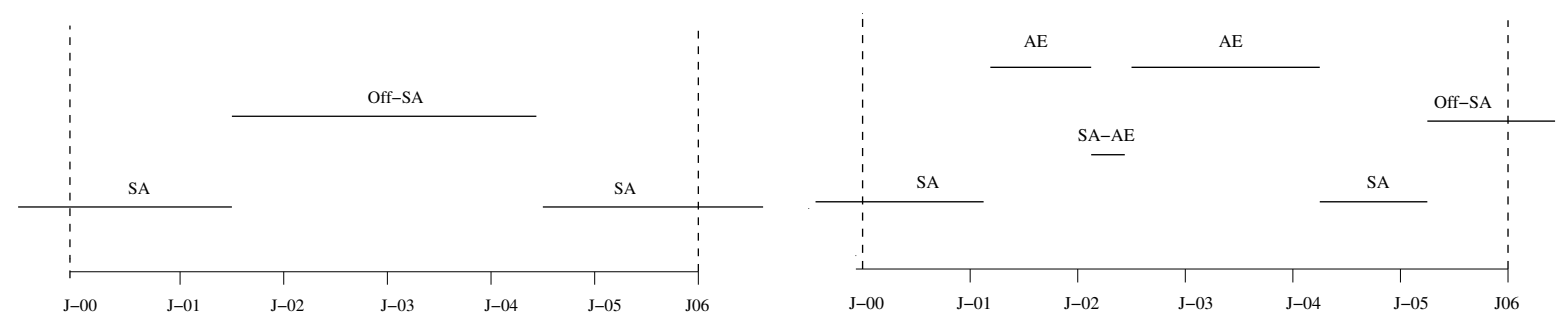

The figure illustrates the complexity of individual histories. It also underscores the many statistical challenges that must be tackled. Indeed, the potential self-selectivity into AE must be accounted for. In addition, the model must take into account the finite duration of the AE program as well as that of the grace period (AE-SA). In both cases, termination involves a discontinuity in the exit rate and a discrete decision to move into a new state. Finally,

\footnotetext{
${ }^{10}$ Despite the fact that over 3,807 single parents participated, as many as 47,311 did not. Observed and unobserved differences could be important determinants of participation. In particular, only those who met their caseload worker or who spent time reading the relevant documentation may have been aware of the existence of the program. These individuals may differ from the others in different aspects.

${ }^{11}$ Left-censored spells are denoted as "Incomplete" or "Interrupted" in what follows.
} 
left-censored spells must be treated carefully. Different alternatives exist but none are entirely satisfactory. We could for instance focus on the transitions that occur after the implementation of the AE program. This would solve the problem for the participants but not for the nonparticipants. Instead we define separate hazard functions for interrupted and completed spells and we model the initial condition explicitly [see Heckman and Singer (1984) and Ham and LaLonde (1996)].

\subsection{Modelling transition intensities}

Let $m$ denote the number of observed episodes for each individuals (note that $m$ is a random variable). Each episode is characterized by its duration and the state that succeeds it (destination state). In our case, four different states may be observed (SA, Off-SA, AE, AE-SA). Write the endogenous variables as $\left(\delta_{1}, r_{1}\right),\left(\delta_{2}, r_{2}\right), \ldots,\left(\delta_{m} r_{m}\right)$, where $\delta_{j}$ is the duration of the $j^{\text {th }}$ episode and $r_{j}$ is the destination state that brings it to an end.

We use a conventional multi-state multi-episode model that specifies the joint distribution of the $m$ continuous and discrete variables $\left(\delta_{j}, r_{j}\right), j=1, \ldots m$ [see Lawless (2003), Mealli and Pudney (2003)]. More precisely, let $f\left(\delta_{j}, r_{j} \mid X_{j}, \nu\right)$ be the joint density of the duration and destination state of the $j^{\text {th }}$ spell. The density is conditional on a vector of observed characteristics which may include earlier state and duration variables to allow for lagged state dependence. ${ }^{12}$ The variables are all spell-specific and are assumed constant over the duration of a given spell. The term $\nu$ is a vector of unobserved individual random effects that are constant over time. This constancy is likely to generate serial dependance in the sequence of episodes.

The last observed spell is still in progress in December 2005. For this censored spell, the duration and the destination state are unknown. Its distribution is thus characterized by a survivor function, $S\left(\delta_{m} \mid X_{m}, \nu\right)$, which gives the conditional probability that the $m^{\text {th }}$ spell lasts at least $\delta_{m}$ months. Finally, as mentioned above, the density function of the initial spell is estimated separately from the the density of the subsequent spells to account for left-censoring. We thus write $f^{0}(\cdot)$ and $S^{0}(\cdot)$ for the initial spell and $f^{1}(\cdot)$ and $S^{1}(\cdot)$ for subsequent spells. Conditional on the observed covariates, $X=\left\{X_{0}, X_{1}, X_{2}, \ldots, X_{m}\right\}$, and the unobserved effects,

\footnotetext{
${ }^{12}$ See Doiron and Gorgens (2008) for a recent and in-depth analysis of state dependance in labour market outcomes.
} 
$\nu$, the joint distribution of $r_{0}, \delta_{1}, r_{1}, \delta_{2}, r_{2}, \ldots, \delta_{m}, r_{m}$, is given by:

$$
\begin{aligned}
f\left(r_{0}, \delta_{1}, r_{1}, \ldots, \delta_{m}, f_{m}\right)= & \underbrace{\operatorname{Pr}\left(r_{0} \mid X_{0}, \nu\right)}_{(a)} \times \underbrace{\left\{f^{0}\left(\delta_{1}, r_{1} \mid X_{1}, \nu\right)^{1-c} S^{0}\left(\delta_{1} \mid X_{1}, \nu\right)^{c}\right\}}_{(b)} \times \\
& \underbrace{\left[\prod_{j=2}^{m-2} f^{1}\left(\delta_{j}, r_{j} \mid X_{j}, \nu\right)\right]} \times \underbrace{S^{1}\left(\delta_{m} \mid X_{m}, \nu\right)} .
\end{aligned}
$$

The expression (a) describes the probability of observing the initial state (Off-SA or SA). The term $(b)$ is the density of the first spell. If the episode is not right-censored, then $c=0$, otherwise $c=1 .{ }^{13}$ Thus non-participants who experiment only one episode are both left and right-censored and contribute $S^{0}\left(\delta_{1} \mid x_{1}\right)$ to the likelihood function. The expression $(c)$ is the joint density of all intermediate spells. Finally, the expression $(d)$ is the survivor function for the ultimate spell.

The transition components of the model $[\operatorname{Pr}(\cdot), f(\cdot)$ and $S(\cdot)]$ are based on destinationspecific transition intensity functions. These give the instantaneous probability of exit to a specific destination at a particular time conditional on no previous exit having occurred. Thus, for a given episode, and irrespective of the state of origin, the transition intensity function into state "l", $\lambda_{l}(t \mid X, \nu)$, is given by:

$$
\operatorname{Pr}(r=l, \delta \in(t, t+d t) \mid \delta \geq t, X, \nu)=\lambda_{l}(t \mid X, \nu) d t,
$$

where $\mathrm{X}$ is spell-specific as mentioned above. The administrative data is constructed in such a way that a given episode can never be observed to be followed by an episode of the same type. The joint probability of exit route $l$ and duration $\delta$ is given by:

$$
f^{n}(l, \delta \mid X, \nu)=\lambda_{l}^{n}(\delta \mid X, \nu) \exp \left[-\sum_{j \neq l} I_{j}^{n}(\delta \mid X, \nu)\right],
$$

where $I_{j}^{n}(\delta \mid X, \nu)$ is the $j^{\text {th }}$ integrated hazard:

$$
I_{j}^{n}=\int_{0}^{\delta} \lambda_{j}^{n}(t \mid X, \nu) \mathrm{d} t, \quad n=\{0,1\}
$$

where $n$ indexes the functions according to whether they apply to the first or subsequent spells. Because the random effects, $\nu$, are unobserved it must be integrated out of the likelihood

\footnotetext{
${ }^{13}$ Recall from Table 4 that the first spell of a significant proportion of non-participants is right-censored.
} 
function. The unconditional likelihood function can thus be written as:

$$
\begin{aligned}
\ln L= & \sum_{i=1}^{N} \ln \left\{\int \operatorname{Pr}\left(r_{0} \mid X_{0}, \nu\right) \times\left\{f^{0}\left(\delta_{1}, r_{1} \mid X_{1}, \nu\right)^{1-c} S^{0}\left(\delta_{1} \mid X_{1}, \nu\right)^{c}\right\} \times\right. \\
& {\left.\left[\prod_{j=2}^{m-2} f^{1}\left(\delta_{j}, r_{j} \mid X_{j}, \nu\right)\right] \times S^{1}\left(\delta_{m} \mid X_{m}, \nu\right) \mathrm{d} G(\nu)\right\}, }
\end{aligned}
$$

where $G(\nu)$ is the distribution function of $\nu$.

\subsection{Unobserved heterogeneity}

The next issue that must be addressed to make the model amenable to estimation is to specify the manner in which unobserved heterogeneity enters the above specification. Most applications rely on the work of Heckman and Singer (1984) and approximate arbitrary continuous distributions using a finite number of mass points [see Gritz (1993), Ham and Rea (1987), Doiron and Gorgens (2008)]. A number of recent papers use flexible specifications that allow the heterogeneity terms to be correlated across states [see Ham and LaLonde (1996), Eberwein et al. (2002)]. These specifications are sometimes referred to as single or double-factor loading distributions and are also based on a finite set of mass points.

Our setting involves four distinct states. In addition, we distinguish between complete and incomplete SA and Off-SA spells, we control for the initial condition and allow for a discontinuity in the AE-SA state (see below). The above approach is impractical in our setting as it would involve too many parameters. Instead we use a two-factor specification, where each of the two random effects are constant over time and linked to a particular state of origin rather than destination. To fix ideas, let $\nu=\left(\nu_{1}, \ldots, \nu_{K}\right)$ be a vector of unobserved heterogeneity variables, with $\nu_{k}$ an origin-specific component $(k=1, \ldots, K)$. Ideally, the joint distribution of the unobserved heterogeneity terms should not be independent. Consider a two-factor loading model [see Van den Berg (1997)] such that

$$
\nu_{k}=\exp \left(\theta_{k}^{1} \xi_{1}+\theta_{k}^{2} \xi_{2}\right)
$$

where $\nu_{k}$ is the random effect associated with state $k, \theta_{k}^{1}$ and $\theta_{k}^{2}$ are loading factors for state $k$, and $\xi_{1}$ and $\xi_{2}$ are independent random draws from the standard normal distribution. ${ }^{14}$ To insure identification of the parameters, we impose $\theta_{k}^{1}=1, k \geq 2$ and $\theta_{k}^{2}=1, k=1$. It can easily be shown that the correlation between $\log \left(\nu_{k}\right)$ and $\log \left(\nu_{l}\right)$ is given by:

$$
\rho_{k l}=\frac{\theta_{k}^{1} \theta_{l}^{1}+\theta_{k}^{2} \theta_{l}^{2}}{\sqrt{\left(\theta_{k}^{1}\right)^{2}+\left(\theta_{k}^{1}\right)^{2}} \sqrt{\left(\theta_{k}^{2}\right)^{2}+\left(\theta_{k}^{2}\right)^{2}}} .
$$

\footnotetext{
${ }^{14}$ A similar approach has been used by Bonnal et al. (1997), Mealli and Pudney (2003) and Gilbert et al. (2001).
} 
A positive correlation between states $k$ and $l$ indicates that unobserved characteristics that favour a (conditionally on $X$ ) high exit rate from state $k$ are likely to favour a high exit rate from state $l$ as well.

\subsection{Initial state}

Recall from Tables 4 and 5 that individuals in our sample are observed in state Off-SA or SA in January 2000. We model the initial state indicator as a binomial logit structure:

$$
\operatorname{Pr}\left(r_{0}=S A \mid X_{0}, \nu_{0}\right)=\frac{\exp \left(X_{0} \gamma_{0}+\nu_{0}\right)}{1+\exp \left(X_{0} \gamma_{0}+\nu_{0}\right)}
$$

where $\gamma_{0}$ is an appropriately dimensioned vector of parameters and $\nu_{0}$ is a heterogeneity term that is specific to the logit component. The parameter vector associated with Off-SA is implicitly normalized to zero. The probability of the initial state is thus correlated to the other states through the unobserved heterogeneity term.

\subsection{Specification of transition intensity functions}

The model involves a large number of potential transitions. Ideally, we should estimate a set of parameters for each origin-destination combination. Likewise, the transition intensity functions should we as flexible as possible. Non-parametric specifications are the most flexible but they entail many parameters. They are useful when studying single spells data. But in our context they simply are not practical. Our strategy consists in estimating destination-specific transition intensity functions. We allow the intensity functions into SA and Off-SA to depend on past $\mathrm{AE}$ participation through dummy variables. We make a distinction between complete

and incomplete program participation as there is some evidence that early termination may have either a positive or negative impact on future spell durations [see Mealli, Pudney and Thomas (1996)]. The basic specification we use is the log-logistic form:

$$
\lambda_{l}=\frac{\exp \left(X_{l} \beta_{l}+\nu_{l}\right) \kappa_{l} \alpha_{l} t^{\alpha_{l}-1}}{1+\exp \left(X_{l} \beta_{l}+\nu_{l}\right) \kappa_{l} t_{l}^{\alpha}}
$$

where $X_{l}$ is a row-vector of observable characteristics (including possibly past AE participation), $\beta_{l}$ is an appropriately dimensioned destination-specific vector of parameters, and $\kappa_{l}$ and $\alpha_{l}$ are destination-specific parameters. The associated survivor function is given by:

$$
S_{l}=\frac{1}{1+\exp \left(X_{l} \beta_{l}+\nu_{l}\right) \kappa_{l} t_{l}^{\alpha}} .
$$

The log-logistic form is flexible enough to allow a non-monotone hazard. ${ }^{15}$

\footnotetext{
${ }^{15}$ Gritz (1993) also uses a log-logistic specification.
} 
One special feature of AE calls for a modification of the traditional transition model outlined above. Recall that individuals are allowed not to meet the program's requirement for a maximum of four months. On the fourth month they lose eligibility and most either move into Off-SA or SA. We must thus allow for a discontinuity in the destination state probabilities conditional on the "grace period" having ended. The transition structure operates normally until the limit is reached, at which point a separate logistic model comes into play. ${ }^{16}$ Thus, for an exhausted AE-SA spell,

$$
\operatorname{Pr}\left(r=S A \mid X, \nu_{0}\right)=\frac{\exp \left(X \gamma_{G P}+\nu_{0}\right)}{1+\exp \left(X \gamma_{G P}+\nu_{0}\right)} .
$$

This specification is identical to the initial condition logit. Because relatively few individuals exhaust the grace period, we assume that the heterogeneity term is the same as that of the initial condition logit but we allow the slope parameters, $\gamma_{G P}$, to differ. Furthermore, the parameter vector associated with Off-SA is implicitly normalized to zero.

The main problem with the estimation of the likelihood function (3) is the integration of the unobserved heterogeneity. Let $\hat{l}_{i}\left(\nu^{h}\right)$ denote the contribution of individual $i$ to the likelihood function for a given draw $\nu^{h}=\nu_{1}^{h}, \nu_{2}^{h}, \ldots, \nu_{K}^{h}$. The log-likelihood we maximize is the following:

$$
\widehat{\ln L}=\sum_{i=1}^{N} \ln \left(\frac{1}{H} \sum_{h=1}^{H} \hat{l}_{i}\left(\nu^{h}\right)\right)
$$

where $H$ is the number of draws. The maximization of the simulated likelihood function yields consistent and efficient parameter estimates if $\sqrt{N} / H \rightarrow 0$ when $H \rightarrow+\infty$ and $N \rightarrow+\infty$ [see Gouriéroux and Monfort(1991, 1996)]. While the literature has established that $H=20$ appears adequate [see Laroque and Salanié (1993), Kamionka (1998)], we have chosen $H=100$ instead. ${ }^{17}$

\section{Estimation Results}

\subsection{Parameter Estimates}

The estimates of the slope parameters are reported in Table 6. The first column of the table reports the parameters of the initial state logit model. The parameters must be interpreted as the impact of the associated variables on the probability of being in SA in January 2000 relative to being in Off-SA. According to the table, the probability of being initially on SA

\footnotetext{
${ }^{16} \mathrm{No}$ such adjustment need be made to the duration of AE despite its limited duration because at exhaustion every spell systematically transits into Off-SA. Mealli et al. (1996) were the first to propose to modify the model in this manner to account for an exogenous limit on duration.

${ }^{17}$ The slope parameters are relatively insensitive to the number of draws we use. The loading factors, on the other hand, vary considerably when we increase $H$ from 10 to 40 . They stabilize once we reach $H=50$.
} 
increases with age, being female, having more children, being born in Canada, and living in Montreal. Not surprisingly, more schooling increases the probability of being off the rolls.

Columns (2)-(8) report the parameter estimates of observed characteristics on the destinationspecific intensity functions. Columns (2)-(4) relate to the first (incomplete) spell, i.e. $f^{0}(\cdot)$, whereas columns (5)-(8) relate to subsequent spells, i.e. $f^{1}(\cdot)$. The parameter estimates can be read pairwise. For instance, columns (2) and (5) focus on the impact of observed characteristics on the transitions into Off-SA. The sign of each parameter remains the same in both columns, but their magnitude increases substantially in the complete spells. Irrespective of the state of origin, it is found that more schooling increases the transitions into Off-SA. On the other hand, older individuals and larger families appear to have lower transition rates. While Gender and Born in Canada have no statistically significant impacts on transitions into Off-SA during the first spell, they both have a negative and highly significant impact on the subsequent spells.

A similar comparison between columns (3) and (6) reveals interesting results. When transiting into SA, Gender, Born in Canada and Montreal have essentially the same parameter estimates in the incomplete and complete spells specifications. On the other hand, Age and Schooling have opposite signs and both remain highly statistically significant. This is the only case in which we observe a sign reversal of statistically significant parameters. Note that Age has a negative parameter estimate in each destination of the complete spells specifications. This essentially means that the duration in the states of origin tends to increase with age. Conversely, because Schooling has a positive sign in each destination of the complete spells, it follows that the duration in the states of origin all tend decrease with schooling.

The transitions into AE [columns (4) and (7)] yield qualitatively similar results to those found in Table 3 using a simple probit model. They show that participation in AE increases with schooling but decreases with age. Furthermore, individuals living in Montreal have a lower transition rate into AE. The last column of the table reports the results of fitting a simple logit model on the exit route once the grace period ends. Unfortunately, the model is incapable of predicting the type of transition as very few parameters are statistically significant.

The next panel of the table reports the impact of past AE participation on SA and Off-SA spells. The first line relates to incomplete participation (less than 3 years) while the second line focuses on completed spells. ${ }^{18}$ The parameters measure the impact of $\mathrm{AE}$ on the transitions between SA and Off-SA once participation as been terminated or has reached the time limit. Early termination may result from lower attachment to the labour market. Because we use administrative data, we do not know that exact status of a participant who has left AE for Off-SA. Consequently, the impact of incomplete program participation on Off-SA duration can not be signed unambiguously a priori. Likewise, early termination does not necessarily lead to longer subsequent SA spells and/or shorter Off-SA spells. The limited work experience that was gained during participation may still be beneficial in the post-participation period.

\footnotetext{
${ }^{18}$ Only 197 AE spells were ongoing in December 2005. Furthermore, only 1,019 participants have had cumulative stays of 36 months (26.7\%).
} 
For similar reasons, the impact of complete participation can not be signed unambiguously $a$ priori. Given their limited skills, participants may find it difficult to receive attractive wage offers. Their participation in AE may be tied to a job that conceivably offers very little in terms of skills enhancement. The loss of the wage subsidy at the end of the eligibility period may induce them to move back to SA and behave like non-participants. ${ }^{19}$

The parameter estimates tell an interesting story. To start with, early termination of AE has a positive effect on the transition rates into Off-SA and a negative one on those into SA. Thus participants who leave the program prematurely will spend on average a greater proportion of time off SA than non-participants. Program completion, on the other hand, yields ambiguous results. The transitions into Off-SA and SA are both lower than those observed for non-participants. Because the relation between the duration in a given state and the parameters is highly non-linear, the marginal impact of program completion can not be ascertained by inspection of the their magnitude alone. Simulations must be used to determine their mean impact.

The next line of the table reports the loading factors, i.e. $\theta_{k}^{1}$ and $\theta_{k}^{2}$ from equation (4). Recall that these parameters are origin-specific and affect the exit rate from a given state. To ease interpretation, we report the correlation matrix that is implicitly defined by these parameters [see equation (5)] for the complete spells. Nearly all the correlations are statistically significant, save for the correlation between SA and AE-SA. Thus, conditional on observed characteristics $X$, individuals who are likely to have long Off-SA spells are also likely to have long SA spells and long AE spells. As a matter of fact, the correlation between Off-SA and $\mathrm{SA}$ is 0.992 . This is consistent with the idea that some may cycle relatively rapidly between SA and Off-SA while others have longer cycles.

Table 7 reports the shape parameter of the transition intensity functions. The top panel reports the parameter estimates of $\alpha_{l}$ while the bottom panel reports those of $\kappa_{l}$. Figures 4 and 5 plot various transition intensity functions based on these parameter estimates. The functions are plotted for the average-modal individual in our sample. ${ }^{20}$ Figure 4 focuses on the first spell while Figure 5 focuses on subsequent spells. The flexibility of the log-logistic specification is readily apparent from these figures. Monotonically increasing and decreasing, as well as non-monotonic functions, can result from this particular functional form.

The transition between Off-SA and SA during the first spell increases dramatically in the first few months of 2001. Recall that each individual in our sample qualified for AE when the program was initiated in December 2001. This sharp increase may be indirect evidence that some were induced to move back onto the rolls to establish their eligibility (36 out of the last 45 months on the rolls). This somewhat contrasts with the results from the SSP experiment. Indeed, SSP sampled individuals who were either entering SA or who were already on the rolls. A main concern with the experiment was to the extent to which individuals would delay their

\footnotetext{
${ }^{19}$ This is essentially what was found in the SSP experiment. See Card and Hyslop (2005).

${ }^{20}$ The average-modal individual is female, born in Canada, lives in Montreal, has 1.5 children and 10.5 years of schooling.
} 
exit from SA in order to qualify for the benefits. Data from the Applicant Study found very little evidence of delayed exit behaviour [see Card and Hyslop (2005), Kamionka and Lacroix (2009)]. Our results are more in line with Moffitt (1996) who conjectured that the provision of high quality training programs to welfare recipients may result in increased caseloads. Yet given the small participation rate in $\mathrm{AE}$, the program is unlikely solely responsible for the large increase into SA in the months that proceeded its implementation. The vertical lines

Figure 4: Simulated Transition Intensities - First Spell

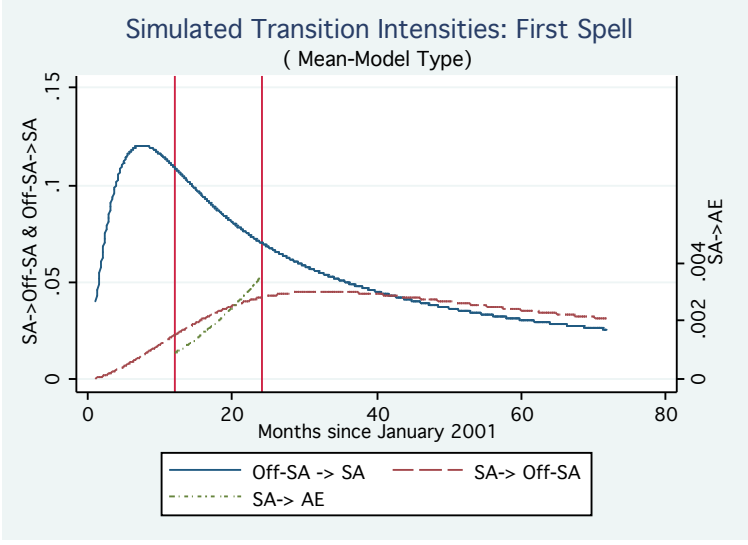

correspond to the twelve-month period during which individuals had to find a full-time job to qualify for AE. The hazard rates between SA and AE correspond to the dotter line and are scaled on the right hand-side of the figure. They vary between 0.001 and 0.0035 per month and yield an overall participation rate of about $2.5 \%$ over the 12 -month period. This is very close to the number of such transitions that occurred during the first spell (967 out of 51,118 individuals). The upward sloping transition rates into $\mathrm{AE}$ is consistent with a decreasing reservation wage as the time limit to qualify approaches. ${ }^{21}$

Figure 5 reports the transition rates between Off-SA and SA for fresh spells. The transitions between the two states are drawn according to the participation status in AE. We distinguish between non-participation, incomplete participation and complete participation. The figure on the left depicts the transition rates between Off-SA and SA. The slopes are very similar to the empirical hazard rates reported in Figure 2. Interestingly, non-participants have the lowest transition rates, followed by those who dropped out of the program early. Completion of AE is found to decrease the likelihood of moving back onto the rolls substantially. The figure on the right-hand side focuses on the transitions between SA and Off-SA. The exit rates are much lower than those reported in Figure 2. This is because the latter figure is based on fresh spells and thus omits the numerous left-censored spells. The spells are consequently heavily skewed

\footnotetext{
${ }^{21}$ If we assume that individuals follow a reservation wage strategy in deciding to leave SA, then it is relatively easy to show that the reservation wage decreases as the time limit to qualify for AE approaches. See Card and Hyslop (2005) and Brouillette and Lacroix (2008).
} 
toward short durations. The simulated transition intensities present interesting features. First,

Figure 5: Simulated Transition Intensities - Fresh Spells
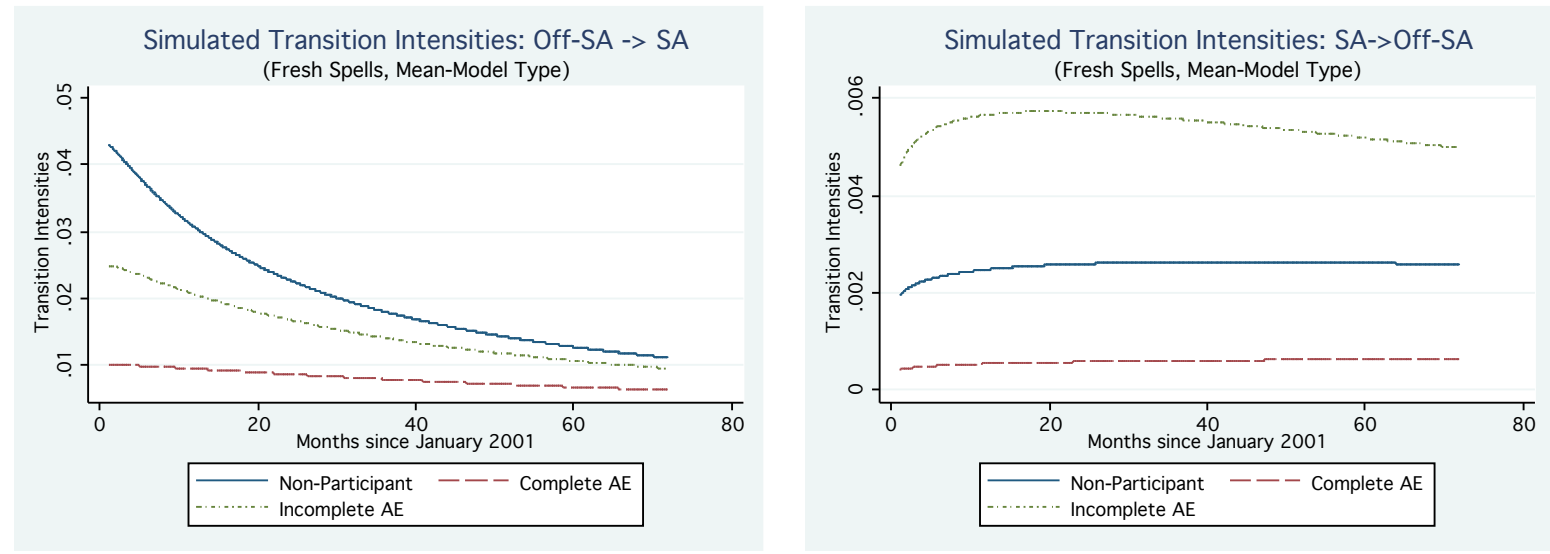

they are relatively flat. This is due to the fact that $\alpha_{l}$ is close to unity and $\kappa_{l}$ is close to zero. Second, incomplete participation is associated with the highest transition rate between SA and Off-SA. Finally, non-participants have higher transition rates than participants who were on AE for three years.

\subsection{Simulation Strategy}

Figure 5 provides mixed evidence on the potential impact of $\mathrm{AE}$ on total time spent on and off SA. In addition, the model structure is sufficiently complex that the parameter estimates can not be interpreted directly. To better understand their meaning, it is best to turn to simulations. These are performed for the same hypothetical individual as above, that is someone who is average with respect to quantitative attributes and modal with respect to qualitative ones. We generate 1,000 six-year work histories via stochastic simulations of the model. These are summarized by computing the average proportion of time spent in each of the four potential states we have considered. To control for endogenous participation in AE, we set the random variables to their mean value (zero). The first set of simulations explores the effects of the covariates by considering slightly different characteristics from the baseline individual. The second set focuses on the unobserved heterogeneity. We once again simulate the work history of the hypothetical individual but vary the random variables while maintaining the characteristics constant.

The algorithm works as follows. The parameters of the initial condition logit are used to determine the initial state. Conditional on the initial state, we next calculate the duration of the three potential transitions (Off-SA $\rightarrow$ SA, SA $\rightarrow$ Off-SA, SA $\rightarrow$ AE) and select the 
shortest. $^{22}$ The $\mathrm{SA} \rightarrow \mathrm{AE}$ transition must be the shortest and occur between months 12 and 24 to be selected, as prescribed by the program. Once the transition type is determined, the parameter estimates of the subsequent spells are used to determine the next transitions until the simulated history spans a total of six years, with the last spell censored. The simulations generate work histories that are comparable to those of Tables 4 and 5, albeit the fact they are conducted on a hypothetical individual and do not account for the sample variability in observed characteristics.

Table 8 reports the main findings. The top panel reports the effect of changing the age of the benchmark individual while maintaining the other characteristics constant. As the individual ages, the mean duration of the Off-SA spells increases significantly while that of the SA spells remain stable. As a result, the proportion of time on SA decreases slightly with age. Interestingly, the model predicts a participation rate of approximately $6 \%$, a figure remarkably close to the observed proportion. Finally, the number of spells over the course of six years is insensitive to age. The second panel of the table focuses on education. We vary the number of years of schooling from 10 to 18. High-school completion entails 12 years of schooling while a university degree more or less corresponds to 17 or 18 years. The simulations show that the duration of SA and Off-SA spells decrease with schooling. As schooling increases individuals transit more rapidly between the two states but the overall proportion of time spent in each of them remains relatively constant. Increases in the number of children lengthen the duration of Off-SA spells and have no impact on the duration of SA spells. Consequently, the proportion of time spent on SA decreases by approximately two percentage points.

While the above changes appear to be relatively small, they need be put into perspective. Recall that only $6 \%$ of SA recipients participate in AE. To look further into this issue, we simulate the likely situation of our benchmark individual in the absence of the AE program. Such a counterfactual is obtained by eliminating the transitions into $\mathrm{AE}$ and by setting the random components to their mean value to avoid the problems of endogenous selection. Table 9 reports the results of simulating the work histories by educational attainment with and without AE. In the world with AE, we only consider spells that occur after the end of AE when computing the mean durations. Thus conditional on participation having ended, we simulate six more years of history so that participants and non-participants may be compared appropriately. Panels (A) and (B) of Table 9 report the simulation results. The difference between the two are shown in panel (C). In general, it is found that the AE program decreases the proportion of time spent on SA by individuals with average educational attainment. Individuals with very low or very high schooling are found to increase their reliance on SA. As shown in the table, the change in the proportion of time on SA varies between -1.8 and 0.8 percentage points.

The above simulations are all conducted under the assumption that the unobserved heterogeneity components are fixed at their mean value of zero and are cast within a six-year time frame. The model can also be used to simulate the sensitivity of the work history with respect

\footnotetext{
${ }^{22}$ We sample from the type I extreme value for the logit parts of the model, and from the distribution of the latent duration for the transition part. The inverse of the relevant cumulative density function is evaluated using uniform pseudo-random numbers.
} 
to the unobserved heterogeneity. We once again consider our representative individual and investigate the consequences of varying the unobserved heterogeneity associated with Off-SA between -2 and 2 standard errors around its mean. Rather than simulating the work history over a six-year time frame, we focus on the duration of fresh SA and Off-SA spells conditional on past AE status. We do this simply by letting the relevant dummy variables equal one or zero as need be. Figure 6 depicts the expected duration of both SA and Off-SA spells. Recall from

Figure 6: Expected Duration of Fresh Spells, by Heterogeneity Group
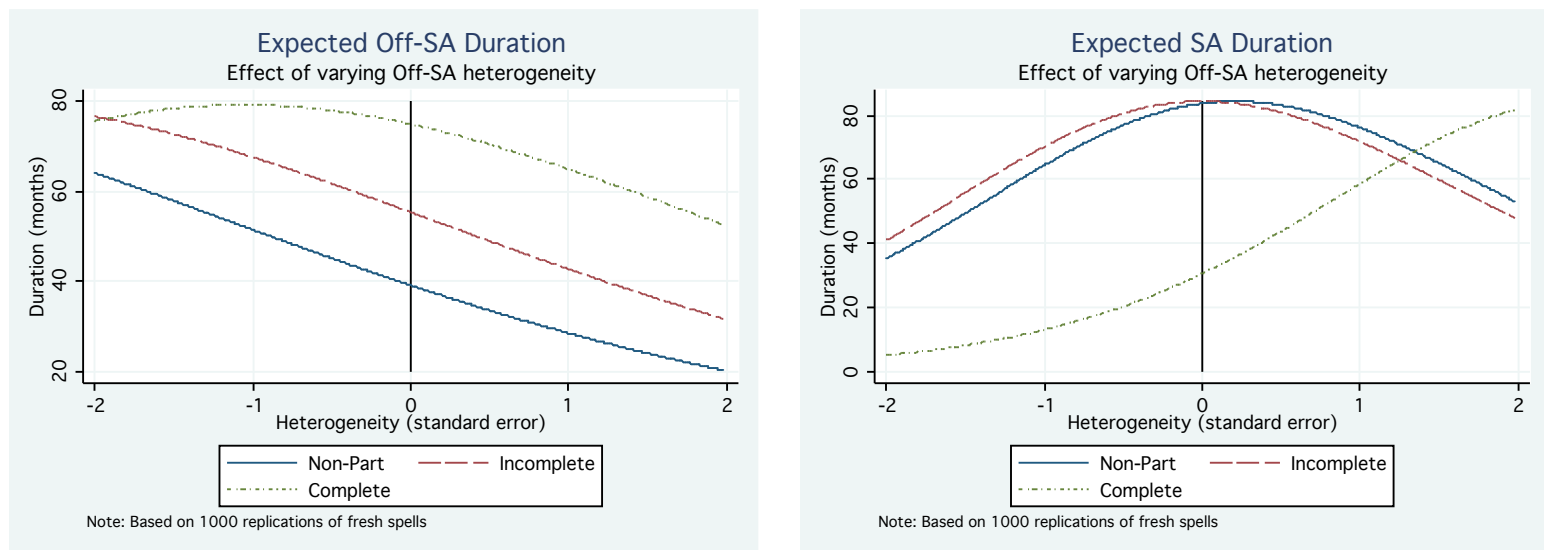

Table 6 that the unobserved heterogeneity components between SA and Off-SA are positively correlated and that the components are origin-specific. A low realization of the unobserved component, $\nu$, will on average decrease both the exit rates from SA and Off-SA and therefore increase the duration. Interestingly, the figure shows that the relation between the duration in both states is not linear. An increase in the unobserved component decreases the duration of Off-SA spells dramatically. Note that the general pattern is consistent with the simulated transition intensities reported in Figure 5: Non-participants have the shortest duration, followed by incomplete participation and complete participation. The mean duration of Off-SA spells is much greater than the sample mean because the spells are not censored. On the other hand, as the unobserved component increases, the duration of the SA spells increases and reaches it maximum value at the mean value of zero for non-participants and early dropouts.

Individuals who remained on $\mathrm{AE}$ for three years have a very distinctive behaviour. For very low values of $\nu$, they have the longest Off-SA spells and the shortest SA spells. As the heterogeneity component increases, the duration of their Off-SA spells decreases but always remain above that of the other two groups. Likewise, the duration of the SA spells increase beyond that of the other two groups only for very high values of $\nu$. Their steady-state reliance on SA is thus by far the lowest. 


\section{Conclusion}

Back in December 2001, the Quebec government implemented the so-called "Action Emploi" (AE) program. It aimed at making work pay for long-term social assistance recipients. AE offered a generous wage subsidy for up to three years to those who left social assistance (SA) within twelve months to take a full-time job. The program was implemented on an experimental basis for a single year. Very little research has looked into the impact of the program on the employment history of the targeted population. Yet, based on little empirical evidence a slightly modified version of the program was implemented on a permanent basis in May 2008 .

The paper investigates the impact of the program on the work history of a large sample of social assistance recipients. We do this by modelling the main features of the program. We focus on the transitions on the labour market starting one year prior to the implementation of the program and up until the end of 2005. Our empirical strategy relies on a multi-state multi-episode transition model. The model accounts for left-censoring, for the initial conditions

problem as well as for the fixed duration of the "grace period" during which participants are entitled not to meet the program requirements. The endogeneity of the participation status is accounted for by treating $\mathrm{AE}$ as a distinct state and by allowing correlated unobserved factors to affect the observed transitions.

Our results show that AE has indeed increased the duration of Off-SA spells and decreased the duration of SA spells slightly. The results vary according to whether participation was interrupted early or not. There is also some evidence that the response to the program varies considerably with the unobserved individual characteristics. Given that only $6 \%$ of the eligible population actually participated in the program, one can conjecture that a larger participation rate would have translated into larger program effects. This conjecture will eventually lend itself to investigation as the new permanent program gets more widely known and as more data become available. 


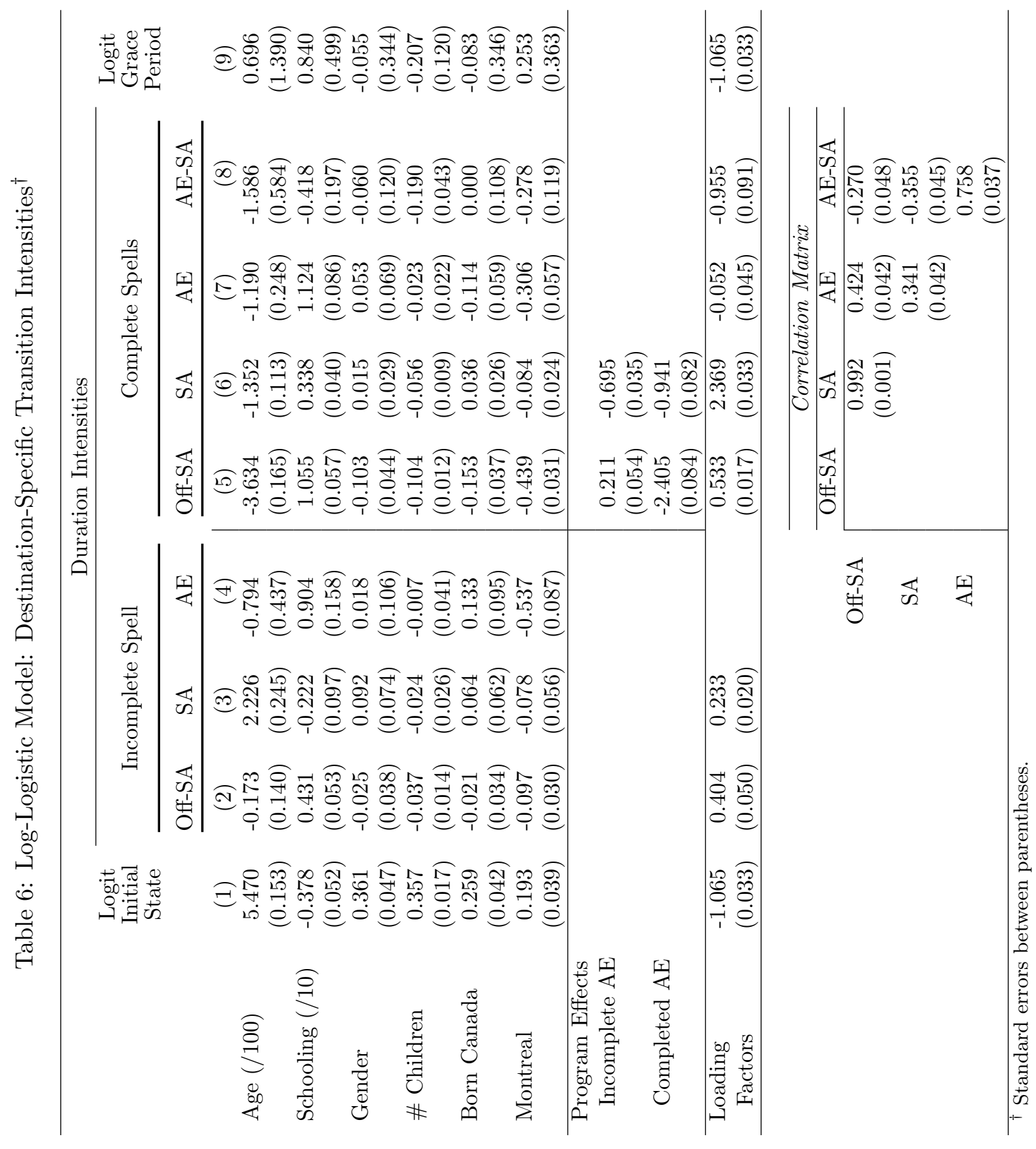


Table 7: Log-Logistic Shape Parameters

\begin{tabular}{|c|c|c|c|c|c|c|c|}
\hline \multirow[b]{3}{*}{ Origin } & \multicolumn{7}{|c|}{ Destination } \\
\hline & \multicolumn{3}{|c|}{ Initial spell } & \multicolumn{4}{|c|}{ Subsequent spells } \\
\hline & Off-SA & SA & $\mathrm{AE}$ & Off-SA & $\mathrm{SA}$ & $\mathrm{AE}$ & AE-SA \\
\hline \multirow[b]{2}{*}{ Off-SA } & \multicolumn{7}{|c|}{$\alpha_{j k}$} \\
\hline & \multicolumn{3}{|c|}{$\begin{array}{c}1.894 \\
(0.039)\end{array}$} & & $\begin{array}{c}1.024 \\
(0.258)\end{array}$ & $\begin{array}{c}0.782 \\
(0.102)\end{array}$ & \\
\hline SA & $\begin{array}{c}2.472 \\
(0.014)\end{array}$ & & $\begin{array}{c}2.993 \\
(0.218)\end{array}$ & $\begin{array}{c}1.110 \\
(0.074)\end{array}$ & & $\begin{array}{l}1.038 \\
(1.367)\end{array}$ & \\
\hline $\mathrm{AE}$ & & & & $\begin{array}{c}2.822 \\
(0.038)\end{array}$ & & \multicolumn{2}{|r|}{$\begin{array}{c}0.745 \\
(0.131)\end{array}$} \\
\hline \multirow[t]{3}{*}{$\mathrm{AE}-\mathrm{SA}^{\dagger}$} & & & & \multicolumn{4}{|c|}{$\begin{array}{l}1.930 \\
(0.103)\end{array}$} \\
\hline & \multicolumn{7}{|c|}{ Destination } \\
\hline & & itial sp & & & & bsequer & t spells \\
\hline \multirow[t]{2}{*}{ Origin } & Off-SA & SA & $\mathrm{AE}$ & Off-SA & $\mathrm{SA}$ & $\mathrm{AE}$ & AE-SA \\
\hline & \multicolumn{7}{|c|}{$\kappa_{j k}($ see note $)$} \\
\hline Off-SA & & $\begin{array}{l}11.486 \\
(0.419)\end{array}$ & & & $\begin{array}{l}52.866 \\
(1.277)\end{array}$ & $\begin{array}{c}1.277 \\
(0.023)\end{array}$ & \\
\hline SA & $\begin{array}{c}0.208 \\
(0.002)\end{array}$ & & $\begin{array}{c}0.000 \\
(0.000)\end{array}$ & $\begin{array}{c}4.113 \\
(0.076)\end{array}$ & & $\begin{array}{c}0.012 \\
(0.000)\end{array}$ & \\
\hline $\mathrm{AE}$ & & & & $\begin{array}{c}0.507 \\
(0.010)\end{array}$ & & & $\begin{array}{l}59.672 \\
(6.922)\end{array}$ \\
\hline $\mathrm{AE}-\mathrm{SA}^{\dagger}$ & & & & & & $\begin{array}{l}38.6: \\
(1.69\end{array}$ & \\
\hline
\end{tabular}

$\dagger$ The parameter is constant across states of origin.

Note: All the $\kappa_{j k}$ parameters are multiplied by 1000 to ease reading. They are all statistically significant. 
Table 8: Simulation Results: Observed Heterogeneity ${ }^{\dagger}$

\begin{tabular}{|c|c|c|c|c|c|}
\hline & \multicolumn{5}{|c|}{ Age } \\
\hline & 20 & 30 & 35 & 40 & 50 \\
\hline Mean duration Off-SA & 18.6 & 19.9 & 20.3 & 21.6 & 22.4 \\
\hline Mean duration SA & 30.9 & 31.1 & 31.1 & 31.1 & 30.6 \\
\hline$\%$ Participants & 6.1 & 6.0 & 6.0 & 7.3 & 4.0 \\
\hline$\%$ time off SA & 28.1 & 28.5 & 28.5 & 29.9 & 30.8 \\
\hline$\%$ time on $\mathrm{SA}$ & 70.5 & 70.1 & 70.4 & 68.2 & 68.3 \\
\hline$\%$ time on $\mathrm{AE}$ & 1.4 & 1.3 & 1.1 & 1.9 & 0.9 \\
\hline \multirow[t]{3}{*}{ Average \# Spells } & 2.7 & 2.7 & 2.6 & 2.6 & 2.6 \\
\hline & \multicolumn{5}{|c|}{ Education } \\
\hline & 10 & 12 & 14 & 16 & 18 \\
\hline Mean duration Off-SA & 16.6 & 16.8 & 16.2 & 15.2 & 14.9 \\
\hline Mean duration SA & 29.5 & 29.4 & 28.0 & 27.2 & 26.3 \\
\hline$\%$ Participants & 6.2 & 5.5 & 5.9 & 7.4 & 7.3 \\
\hline$\%$ time off SA & 24.8 & 25.7 & 26.2 & 26.2 & 26.8 \\
\hline$\%$ time on $\mathrm{SA}$ & 73.6 & 73.0 & 72.4 & 72.3 & 71.8 \\
\hline$\%$ time on $\mathrm{AE}$ & 1.5 & 1.3 & 1.4 & 1.5 & 1.3 \\
\hline \multirow[t]{3}{*}{ Average \# Spells } & 2.9 & 2.9 & 3.0 & 3.1 & 3.3 \\
\hline & \multicolumn{5}{|c|}{ \# of Children } \\
\hline & 1 & 2 & 3 & 4 & 5 \\
\hline Mean duration Off-SA & 16.2 & 16.9 & 17.7 & 18.9 & 18.2 \\
\hline Mean duration SA & 29.4 & 29.3 & 30.0 & 29.7 & 30.1 \\
\hline$\%$ Participants & 6.9 & 5.5 & 5.6 & 5.0 & 5.3 \\
\hline$\%$ time off SA & 24.9 & 25.8 & 26.0 & 27.6 & 26.6 \\
\hline$\%$ time on $\mathrm{SA}$ & 73.5 & 72.9 & 72.9 & 71.4 & 72.1 \\
\hline$\%$ time on $\mathrm{AE}$ & 1.5 & 1.2 & 1.1 & 1.1 & 1.2 \\
\hline Average \# Spells & 2.9 & 2.9 & 2.8 & 2.8 & 2.7 \\
\hline
\end{tabular}

$\dagger$ Based on 1000 replications, average-modal individual 
Table 9: Simulation Results: Hypothetical Individual With and Without $\mathrm{AE}^{\dagger}$

\begin{tabular}{|c|c|c|c|c|c|}
\hline \multirow{6}{*}{$\begin{array}{l}\text { Mean duration Off-SA } \\
\text { Mean duration SA } \\
\% \text { time off SA } \\
\% \text { time on SA }\end{array}$} & \multicolumn{5}{|c|}{ (A) Education with $A E$} \\
\hline & 10 & 12 & 14 & 16 & 18 \\
\hline & 21.6 & 21.2 & 20.7 & 20.3 & 18.9 \\
\hline & 30.9 & 29.8 & 30.0 & 29.2 & 28.6 \\
\hline & 29.3 & 30.2 & 29.5 & 30.0 & 28.6 \\
\hline & 70.7 & 69.8 & 70.5 & 70.0 & 71.4 \\
\hline & \multicolumn{5}{|c|}{ (B) Education without $A E$} \\
\hline & 10 & 12 & 14 & 16 & 18 \\
\hline Mean duration Off-SA & 22.3 & 21.2 & 19.6 & 19.9 & 19.7 \\
\hline Mean duration SA & 30.6 & 30.1 & 30.3 & 29.9 & 28.8 \\
\hline$\%$ time off SA & 30.1 & 29.3 & 27.7 & 29.0 & 29.1 \\
\hline \multirow[t]{3}{*}{$\%$ time on $\mathrm{SA}$} & 69.9 & 70.7 & 72.3 & 71.0 & 70.9 \\
\hline & \multicolumn{5}{|c|}{ Difference between $(A)$ and $(B)$} \\
\hline & 10 & 12 & 14 & 16 & 18 \\
\hline Mean duration Off-SA & -0.7 & 0.0 & 1.1 & 0.4 & -0.8 \\
\hline Mean duration SA & 0.3 & -0.3 & -0.3 & -0.7 & -0.2 \\
\hline$\%$ time off SA & -0.8 & 0.9 & 1.8 & 1.0 & -0.5 \\
\hline$\%$ time on $\mathrm{SA}$ & 0.8 & -0.9 & -1.8 & -1.0 & 0.5 \\
\hline
\end{tabular}

$\dagger$ Based on 1000 replications, average-modal individual 


\section{References}

Bonnal, L., D. Fougère, and A. Sérandon (1997) 'Evaluating the impact of French employment policies on individual labour market histories.' The Review of Economics Studies 64(4), 683-718

Brouillette, Dany, and Guy Lacroix (2008) 'Heterogeneous treatment and self-selection in a wage subsidy experiment.' IZA Working Paper 3738

Card, D., and D.R. Hyslop (2005) 'Estimating the effects of a time-limited earnings subsidy for welfare leavers.' Econometrica

Doiron, D., and T. Gorgens (2008) 'State dependence in youth labor market experiences, and the evaluation of policy interventions.' Journal of Econometrics 145, 81-97

Eberwein, C, J. C. Ham, and R. J. LaLonde (2002) 'Alternative methods of estimating program effects in event history models.' Labour Economics 9, 249-278

Gilbert, L., T. Kamionka, and G. Lacroix (2001) 'Les effets des dispositifs publics de retour à l'emploi destinés aux jeunes hommes défavorisés au Québec.' Économie et Statistique $345,55-94$

Gouriéroux, C., and A. Monfort (1996) Simulation-Based Econometric Methods Core Lectures (Oxford University Press)

Gourriéroux, C., and A. Monfort (1991) 'Simulation based econometrics in models with heterogeneity.' Annales d'économie et de statistique 20(1), 69-107

Gritz, R.M. (1993) 'The impact of training on the frequency and the duration of employment.' Journal of Econometrics 57, 21-51

Ham, J.C., and R.J. LaLonde (1996) 'The effect of sample selection and intitial conditions in duration models: Evidence from experimental data on training.' Econometrica 64(1), 175-205

Ham, J.C., and S.A. Rea (1987) 'Unemployment insurance and male unemployment duration in Canada.' Journal of Labor Economics pp. 325-353

Harknett, K., and L. A. Gennetian (2001) 'How an earnings supplement can affect the marital behaviour of welfare recipients: Evidence from the self-sufficiency project.' Working Paper, SRDC

Heckman, J., and B. Singer (1984) 'A method for minimizing the distributional assumptions in econometric models for duration data.' Econometrica pp. 271-320

Heckman, J.J., R.J. LaLonde, and J.A. Smith (1999) 'The economics and econometrics of active labor market programs.' In Handbook of Labor Economics, ed. O. Ashenfelter and Eds. D. Card (North-Holland) chapter

Kamionka, T. (1998) 'Simulated maximum likelihood estimation in transition models.' Econometrics Journal 1, C129-C153

Kamionka, Thierry, and Guy Lacroix (2009) 'Assessing the External Validity of an Experimental Wage Subsidy.' Forthcoming, Annales d'Économie et de Statistique

Laroque, G., and B Salanié (1993) 'Simulation-based estimation of models with lagged latent variables.' Journal of Applied Econometrics 8, S119-S133 
Lawless, J.F. (2003) 'Event history analysis and longitudinal surveys.' In Analysis of Survey Data, ed. R.L. Chambers and C.J. Skinner (John Wiley and Sons) chapter 15, pp. 221-243 Lise, Jeremy, Shannon Seitz, and Jeffrey A. Smith (2005) 'Equilibrium policy experiments and the evaluation of social programs.' Queen's University, WP 1076

Mealli, F., and S. Pudney (2003) 'Applying heterogenous transition models in labour economics: The role of youth training in labour market transitions.' In Analysis of Survey Data, ed. R.L. Chambers and C.J. Skinner (John Wiley and Sons) chapter 16, pp. 245-274 Mealli, F., S. Pudney, and J. Thomas (1996) 'Training duration and post-training outcomes: A duration-limited competing risks model.' Economic Journal 106(435), 422-433

Michalopoulos, C., D. Card, L. A. Gennetian, K. Harknett, and P. K. Robins (2000) 'The self-sufficiency project at 36 months: Effects of a financial work incentive on employment and income.' Working Paper, SRDC

Moffitt, R. (1996) 'The effect of employment and training programs on entry and exit from the welfare caseload.' Journal of Policy Analysis and Management 15(1), 32-50

Morris, P., and C. Michalopoulos (2000) 'The self-sufficiency project at 36 months: Effects on children of a program that increased parental employment and income.' Working Paper, SRDC

Quets, G., P. K. Robins, E. C. Paan, C. Michalopoulos, and D. Card (1999) 'Does SSP -Plus increase employment? the effect of adding services to the self-sufficiency project's financial incentives.' Working Paper, SRDC

Van den Berg, G.J. (1997) 'Association measures for durations in bivariate hazard rate models.' Journal of Econometrics 79(2), 221-245 